\title{
Acetabular reinforcement ring in primary total hip arthroplasty: a minimum 10-year follow-up
}

\author{
Hassan Sadri · Grégoire Pfander · Klaus-Arno Siebenrock • Moritz Tannast • \\ Peter Koch $\cdot$ Hiroshi Fujita $\cdot$ Peter Ballmer $\cdot$ Reinhold Ganz
}

Received: 19 July 2007 / Published online: 18 March 2008

(C) Springer-Verlag 2008

\begin{abstract}
Introduction We report the results of a titanium acetabular reinforcement ring with a hook (ARRH) in primary total hip arthroplasty (THA), which was introduced in 1987 and continues to be used routinely in our center. The favorable results of this device in arthroplasty for developmental dysplasia and difficult revisions motivated its use in primary THA. With this implant only minimal acetabular reaming is necessary, anatomic positioning is achieved by placing the hook around the teardrop and a homogenous base for cementing the polyethylene cup is provided.

Materials and methods Between April 1987 and December 1991, 241 THAs with insertion of an ARRH were performed in 178 unselected, consecutive patients (average age 58 years; range $30-84$ years) with a secondary osteoarthrosis in $41 \%$ of the cases.

Results At the time of the latest follow-up, 33 patients (39 hips) had died and 17 cases had been lost to follow-up. The median follow-up was 122 months with a minimum of 10 years. Eight hips had been revised, leaving 177 hips in 120 living patients without revision. Six cups were revised because of aseptic loosening. Two hips were revised for sepsis. The mean Merle d'Aubigné score for the remaining hips was 16 (range 7-18) at the latest follow-up. For aseptic
\end{abstract}

H. Sadri · G. Pfander · K.-A. Siebenrock · M. Tannast ( $\square)$.

P. Koch $\cdot$ H. Fujita $\cdot$ R. Ganz

Department of Orthopaedic Surgery,

Inselspital, University of Bern, 3010 Bern, Switzerland

e-mail: moritz.tannast@insel.ch

P. Ballmer

Clinic for Orthopaedic Surgery, Spital Thun, Thun, Switzerland loosening, the probability of survival of the cup was 0.97 (95\% confidence interval, 0.94-0.99). However, analysis of radiographs implied loosening in seven other cups without clinical symptoms.

Conclusions The results of primary THA using an acetabular reinforcement ring parallel the excellent results of these implants often observed in difficult primary and revision arthroplasty at a minimum of 10 years. Survivorship is comparable to modern cementless implants. Medial migration that occurs with loosening of the acetabular component seems to be prevented with this implant. Radiographic loosening signs can exist without clinical symptoms.

Keywords Total hip arthroplasty - Long-term results . Acetabular reinforcement ring with hook $\cdot$ Cemented

\author{
Abbreviations \\ THA Total hip arthroplasty \\ ARRH Acetabular reinforcement ring with hook \\ OA Osteoarthritis
}

\section{Introduction}

Previous reports of total hip arthroplasty (THA) performed with the use of a Müller reinforcement ring have demonstrated favorable results in revision and primary hip surgery $[1,14,37]$. Revision rates for aseptic loosening have varied between 1 and $8 \%$ at an average follow-up of 6.4-10 years $[1,14,37]$.

The use of the acetabular reinforcement ring with a hook (ARRH) has certain advantages and is even more versatile. This implant requires less reaming of subchondral bone and thus preserves bone stock. It also provides a uniform base for cementation of the polyethylene cup and accommodates 
for irregular acetabular orientation especially in difficult cases of dysplasia or those with abnormal version. The ARRH allows for anatomic positioning of the acetabular component with the placement of the component's hook around the teardrop.

The ARRH could be shown to have excellent long-term results in revision cases, hip dysplasia and avascular necrosis of the femoral head [21, 34, 35]. Based on the promising results in these complex cases, this device has been used routinely in our unit since 1987 for all primary THA regardless of bone quality or deficits. In this report, we present the results of the first 241 consecutive primary total hips performed using the ARRH with a minimum 10-year follow-up. The purpose of the study was to evaluate the performance of this acetabular implant when used routinely in all cases of primary THA and to compare it to survival rates of cemented and cementless cups available in literature.

\section{Materials and methods}

\section{Patient demographics}

Between 1987 and 1991, 178 consecutive unselected patients underwent 241 cases of primary THA by two of the authors (PB, RG). The average patient age at the time of the index procedure was 58 years (range 30-84 years). There were 102 men and 76 women. The majority of the 241 hips had a diagnosis of primary osteoarthritis [OA, $n=142$ (59\%)], followed by dysplasia $[n=41(17 \%)]$, osteonecrosis $[n=34(14 \%)]$, post-traumatic OA $[n=12(5 \%)]$, rheumatoid arthritis $[n=7(3 \%)]$ and other diagnoses $[n=5$ $(2 \%)$. Fifty cases $(21 \%)$ had a previous hip operation including intertrochanteric osteotomy in 38 , open reduction and internal fixation of the proximal femur in 8 and periacetabular osteotomy in 4.

Of the 241 hips, 33 (19\%) hips did not reach the 10-year follow-up mark due to death of the patients prior to it and $17(10 \%)$ hips were lost to follow-up. Last clinical information on these patients was obtained by contacting the family and/or the primary care physician. This information as well as the last available clinical and radiographic chart records are reported separately.

In the remaining 185 hips, 8 had undergone revision surgery. This left 177 hips available for review at a median of 122 months after the index operation.

\section{Implant}

During the time of the study period the original ARRH component (Centerpulse, Winterthur, Switzerland) consisted of a titanium (Protema-Tcp) alloy with a smooth electropolished surface without any ongrowth potential (Fig. 1). The ring is available in sizes ranging from 38 to $64 \mathrm{~mm}$ and is combined with a cemented low profile polyethylene cup that typically is chosen $2-4 \mathrm{~mm}$ smaller. The design has only been changed to a rough, sand-blasted back surface since its introduction. The head of the femoral implant measured $28 \mathrm{~mm}$ in 95 cases; $22 \mathrm{~mm}$ in 86 and $32 \mathrm{~mm}$ in the remaining 60 cases. The femoral stem implanted was a Müller-type straight design in 217 cases and in 24 patients a smaller dysplasia variant was used.

\section{Operative procedure}

The patient was placed in the supine of the lateral decubitus position and a direct transgluteal approach [4] was performed in all the cases except in four where a trochanteric osteotomy was used. The acetabulum was prepared with standard reamers. Progressive reaming was continued until spot-like bleeding of the subchondral bone occurred. Small defects between bone and the ring surface were grafted with autologous cancellous bone from the resected femoral head.

Ninety-one hips required some form of osseous acetabular reconstruction using autologous bone graft in all cases. Acetabular reconstruction included cortico-cancellous grafts in rim deficiencies due to secondary OA in developmental dysplasia of the hip, avascular necrosis of the femoral head or previous trauma in 14 hips $(6 \%)$. In the remaining 77 hips $(32 \%)$ cancellous bone was used to fill a deep fossa or cavitary defects or cysts of the acetabulum. The teardrop was exposed with a blunt retractor placed at the medial border of the incisura acetabuli. Initial sizing of the ring was performed with a trial component. The hook of the definitive ring is placed around the inferomedial lip of the acetabulum corresponding to the teardrop on the anteroposterior pelvic radiograph [12]. This helps to

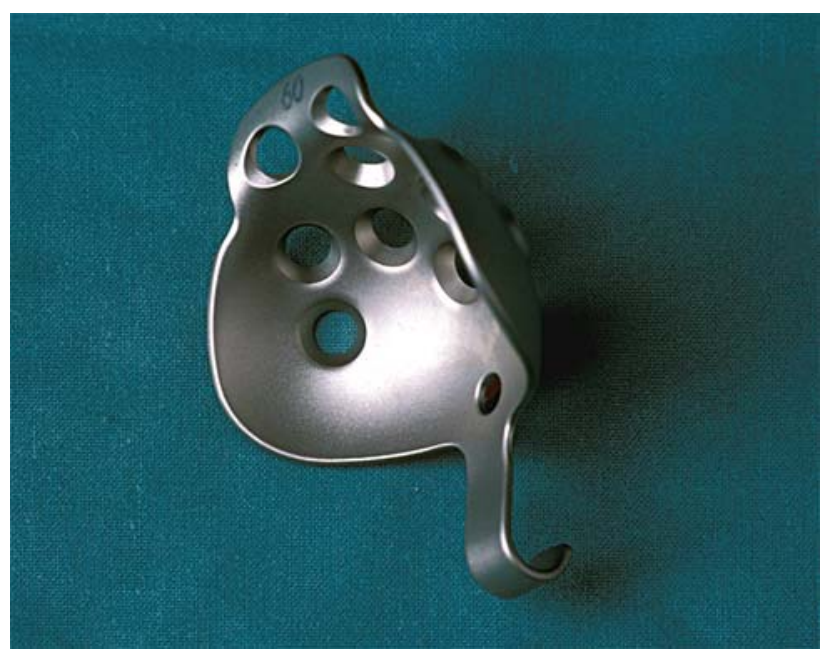

Fig. 1 Image of acetabular reinforcement ring with a hook (ARRH) 
prevent superior or lateral malposition of the acetabular cup $[1,29,34]$. The ring was impacted into the acetabulum until maximal contact was reached between the flange of the prosthesis and the iliac bone. The size of the ring was considered adequate if primary stability was achieved. The elasticity of the titanium ring helps achieve stability when impacted into the acetabulum. The acetabular rim was trimmed to improve contact of the entire periphery of the ARRH. Once the ring was stable, a central and inferior screw was placed in the center of the implant before placing subsequent screws. The ARRH was secured with an average of four (range 3-6) fully threaded $6.5 \mathrm{~mm}$ cancellous screws. The number of screws in each case varied as a function of the holding strength of the screws and the primary stability of the ring. A standard low profile polyethylene cup was cemented into the reinforcement ring. The orientation of the ring itself is less critical than the contact with bone because the cement-polyethylene interface allows a moderate amount of freedom to further improve the position of the cup [21]. Optimal alignment of the acetabular polyethylene component was considered to be $40^{\circ}$ of inclination in the frontal plane and $20^{\circ}$ of anteversion. A Müller-type straight stem was then implanted into the femur using second generation cementing technique.

Postoperatively, all the patients received subcutaneous heparin as prophylaxis against deep venous thrombosis until full weight bearing was achieved. Antibiotics were given preoperatively and for $24 \mathrm{~h}$ after the procedure. Patients were allowed partial weight bearing with $10-15 \mathrm{~kg}$ after the second postoperative day. Unrestricted weight bearing was allowed 6 weeks following the operation.

\section{Follow-up evaluation}

Clinical and radiographic data were obtained preoperatively, postoperatively, and at 5 and 10 years. Clinical evaluation consisted of physical examination, calculation of the Merle-d'Aubigné hip score [25] and administration of a questionnaire requesting data on pain and analgesic medication. The scores were considered excellent when 16 points or greater were obtained and good in the cases between 14 and 15 points. The records of the patients who died and those who were lost to follow-up as well as the last available radiographs at the time of the latest followup were screened for signs of implant loosening. In addition the last treating physician and the families of the deceased persons were contacted to get information about further revision surgeries on the index hips. This information was included into the statistical analysis to estimate implant survival probability. However, further clinical data on these deceased patients from these sources were too vague to be included into the clinical and radiographical results.

\section{Radiographic analysis}

A complete radiographic series included preoperative, postoperative, 5 and 10 year X-rays. Since acetabular anteversion cannot be assessed accurately on anteroposterior pelvic radiographs [39], only the inclination of the ring and the polyethylene cup was measured. These were compared and analysed for radiolucent lines and heterotopic ossification. A postoperative anteroposterior radiograph within 2 weeks was used as reference to determine the initial position of the implant. An acetabular template (Centerpulse, Winterthur, Switzerland) was used to determine any change in the position of the implant $[11,44]$ and the acetabular components were evaluated with the criteria of Johnston et al. [18]. Loosening [11] was defined as (1) greater than $2 \mathrm{~mm}$ of movement of the center of rotation vertically or horizontally (2) greater than $3^{\circ}$ of rotation of the polyethylene cup, (3) progressive radiolucency around the ring and screws, and/or (4) implant failure (a broken hook or broken screws) in combination with one or more of the previous criteria. Heterotopic bone formation was graded with the criteria of Brooker et al. [6]. Polyethylene wear was estimated with a variant of the method described my Livermore [22]. Since the purpose of the study was not to perform a detailed appraisal of the femoral components, we simply used radiographic migration and/or the presence of a continuous radiolucent line extending around its distal aspect of the stem as a sign of definite loosening in the femur. Medical personnel (GP, MT, PK, and HF) who were not associated with the original operation completed all of the radiographic evaluation.

\section{Statistical analysis}

The probability of implant survival was estimated with the Kaplan-Meier product limit method [19]. Failure was defined as revision surgery for any reason. The time to revision was calculated as the time between the date of implantation and the date of revision. Patients without revision were censored at the date of last follow-up or death. Greenwoods formula was used to determine $95 \%$ confidence intervals around the survivorship curves [17]. The Cox proportionalhazards regression model was utilized to identify univariate and multivariate risk factors predictive of failure [9]. Functional outcome measures including pain, walking ability, mobility and Merle d'Aubigné scores were evaluated for normality with the Kolmogorov-Smirnov test, and significant departures were found for each variable. Therefore, preoperative and postoperative scores were compared with the use of nonparametric Wilcoxon signed-rank test. Significance was determined by a $P$ value of less than 0.05 . Statistical analysis was performed with the SPSS software package (version 11.1; SPSS, Chicago, IL, USA). 


\section{Results}

\section{Clinical evaluation}

Of the 120 living patients (177 hips) who had not undergone revision and were available for follow-up, the median Merle d'Aubigné score increased from 8 points to 16 $(P<0.001)$. Good or excellent clinical results were obtained in 165 hips (93\%, Fig. 2). Seven patients (6\%) required regular pain medication and another seven $(6 \%)$ reported mild to moderate pain requiring intermittent analgesia.

The chart and X-ray information of the patients who died or who were lost to follow-up did not suggest implant loosening in these hips. In addition, third party information did not reveal further revision surgeries on the index hip in any of these cases.

\section{Revisions}

Eight hips (3.3\%) required some form of revision procedure (Table 1). In all eight cases the acetabular component was revised. Two hips $(0.8 \%)$ were removed because of septic loosening. One of these cases ultimately was replaced after a two-stage revision protocol. A new ARRH and cemented Müller-type straight stem were again implanted during the second stage. The second case received a Girdlestone arthroplasty. Six cases $(2.8 \%)$ with aseptic cup loosening were recorded at an average of 8 years (range 5152 months) post implantation. In all of these cases but one revised elsewhere, the acetabulum was again reconstructed with the ARRH and combined with morsellized allograft; in four of these five cases an ARRH was chosen which was $2 \mathrm{~mm}$ larger than the previous one. In the fifth case the same ring size was chosen. In four cases with aseptic loosening the stem was revised, too. In two of these cases another Müller straight stem was implanted and in the other two cases a Wagner revision stem was needed. Of the six non-septic revisions, three had an initial diagnosis of dysplasia, two had rheumatoid arthritis and one had multiple previous surgeries secondary to an acetabular fracture. Thus, none of the 142 hips with primary OA underwent revision for aseptic loosening.

\section{Complications}

Eleven hips (5\%) in our series dislocated, six (2.8\%) within the first 3 months after surgery. All the cases were treated with closed reduction under general anesthesia and immobilization for 3 weeks. There were no cases of recurrent instability.

In one patient, an undisplaced trochanteric fracture was noted 3 weeks postoperatively and was treated conservatively. The fracture healed and the patient was satisfied at
Fig. 2 a A 43-year-old male with advanced bilateral osteoarthritis; b Subsequent bilaterateral THA with an ARRH and Mueller-type straight stem with 22-mm head; c Follow-up at 12 years with an excellent clinical result on both sides (Merle d'Aubigné score of 18) and no signs of radiographic loosening
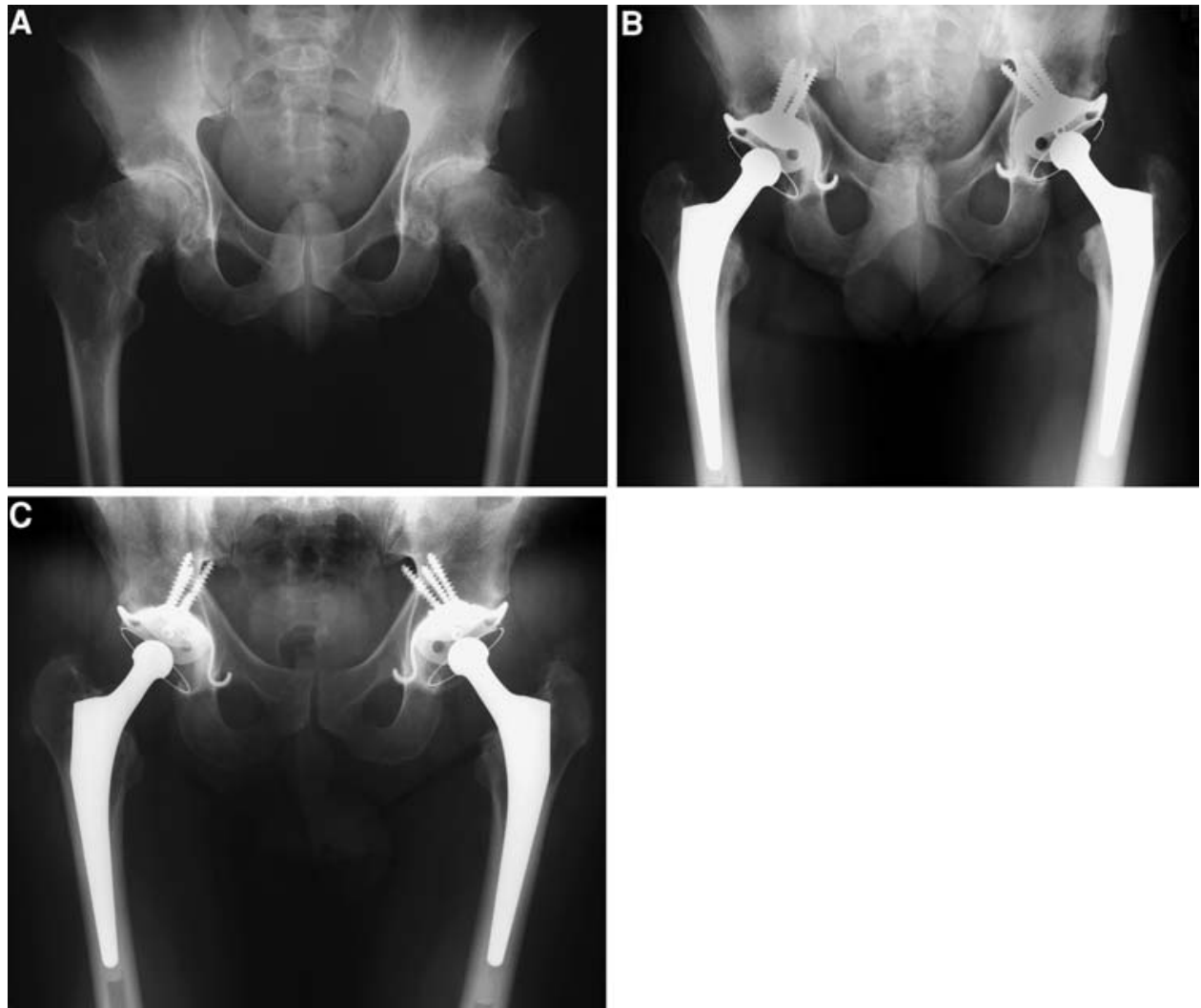
Table 1 Details of cases requiring revision of total hip arthroplasty

\begin{tabular}{lllllll}
\hline Case & $\begin{array}{l}\text { Age } \\
\text { (years) }\end{array}$ & Primary diagnosis & $\begin{array}{l}\text { Time to } \\
\text { revision (months) }\end{array}$ & $\begin{array}{l}\text { Acetabular } \\
\text { revision }\end{array}$ & $\begin{array}{l}\text { Stem } \\
\text { revision }\end{array}$ & Infection \\
\hline 1 & 66 & Postraumatic & 5 & + & + & Yes \\
2 & 52 & Dysplasia & 37 & + & + & \\
3 & 57 & Rheumatoid arthritis & 72 & + & + & \\
4 & 45 & Dysplasia & 88 & + & + & Yes \\
5 & 37 & Rheumatoid arthritis & 96 & + & + & \\
6 & 57 & Posttraumatic & 113 & + & + & \\
7 & 60 & Dysplasia & 120 & + & & \\
8 & 44 & Rheumatoid arthritis & 152 & & & \\
\hline
\end{tabular}

the latest review. Two of the four cases that had a trochanteric osteotomy needed trochanter refixation because of late displacement.

Early postoperative nerve lesions occurred in four patients. These included one incomplete sciatic nerve palsy, one femoral nerve, and two lateral femoral cutaneous nerve lesions. All of these cases resolved after 2 years except for one that required a surgical resection of a lateral femoral cutaneous nerve neuroma. No vascular lesions were noted. Five cases of clinically apparent deep venous thrombosis and two cases of non-lethal pulmonary emboli were treated with prolonged warfarin therapy.

\section{Radiographic evaluation}

Ten-year radiographic follow-up examination, including assessment of preoperative radiographs, was performed in 120 patients (177 hips). There were no cases of dissociation of the polyethylene socket and the ARRH. The immediate postoperative anteroposterior radiographs showed that the hook was not completely placed under the teardrop in 56 cases $(23 \%)$. This did not appear to significantly influence the clinical outcome at 10 years $(P=0.17)$. The superior flange was in contact with host bone in all cases. The ARRH implants ranged from 44 to $58 \mathrm{~mm}$ with the $50 \mathrm{~mm}$ $(41 \%)$ and the $54 \mathrm{~mm}(41 \%)$ sizes being the most frequently used. Polyethylene cup sizes ranged from $40-58$ and in general were $2-4 \mathrm{~mm}$ smaller than the ring. The mean inclination of the ARRH was $36^{\circ}$ (range $15-63^{\circ}$ ). The mean inclination of the polyethylene cup was $39^{\circ}$ (range $15-58^{\circ}$ ).

Seven ARRH were considered definitely loose (Fig. 3) by the radiological criteria mentioned above (Table 2). All but two of these patients had good or excellent Merled'Aubigné scores. One of the two suffered from rheumatoid arthritis and had general pain in both lower extremites and especially her feet. The other patient had grade IV heterotopic ossification with severe hip ankylosis and his walking ability was severely limited by this.

In four cases, there was breakage of a single screw without migration or distinct radiolucencies. All had good to excellent clinical scores. Screw breakage was detected at an average of 27 months (range 12-108) after the index operation. Two revised cases and one radiographically loose acetabular component showed a linear radiolucent line with a maximal width of $2 \mathrm{~mm}$ around the screws. No extensive osteolysis was seen around the screws and no cavitary lesions were seen. None of the radiographically loose ARRH showed protrusion.

One femoral component had migrated more than $5 \mathrm{~mm}$ and was considered radiologically definitely loose. No femoral implant had progressive continuous radiolucent lines extending around the distal stem. Aseptic loosening signs thus were present in 2 (2\%) out of 106 unrevised hips with primary OA. In the 71 unrevised hips with secondary OA loosening was seen in 5 hips (7\%).

Linear polyethylene wear was measured to be on average $0.81 \mathrm{~mm}$ (range $0-4 \mathrm{~mm}$ ) at 10 years. The annual wear rate was thus estimated at $0.08 \mathrm{~mm}$.

Grade IV heterotopic ossification was seen in 1 hip $(0.6 \%)$; grade III, in $10(6 \%)$; grade II in $16(9 \%)$; grade I, in 59 hips (33\%).

Deceased or lost to follow-up patients

Seventeen patients were lost to follow-up prior to reaching the 10-year mark. Thirty-seven patients with 39 THAs deceased within 10 years after surgery resulting in a total of 56 hips with a follow-up information shorter than 10 years. No death could be related to a known complication of the surgery. Death occurred due to underlying medical diseases in 21 patients, due to tumors in 13 patients and due to accidents in 3 patients. Reasons for a lack of a longer follow-up in the 17 non-deceased patients were unknown change in address, chronic illness or being bedridden. Follow-up information was derived from the hospital charts and by contacting the last treating physician or the patient. The follow-up period for the 56 hips averaged 35 months (range 3-92 months). In none of these cases a further surgery on the affected side has been performed. In addition, there was no evident loosening of the THA reported. 
Fig. 3 a A 64-year-old woman with secondary OA on the left side due to osteonecrosis of the femoral head. There is acetabular bone loss and cyst formation in the main weight bearing area; b THA was performed using cancellous autograft from the femoral head and a $50^{\circ}$ inclination of the ARRH; $\mathbf{c}$ After 5 years there was aseptic failure of the acetabular component with breakage of the hook (arrow) and craniolateral migration of the ARRH

Table 2 Details of cases with evidence of radiographic loosening
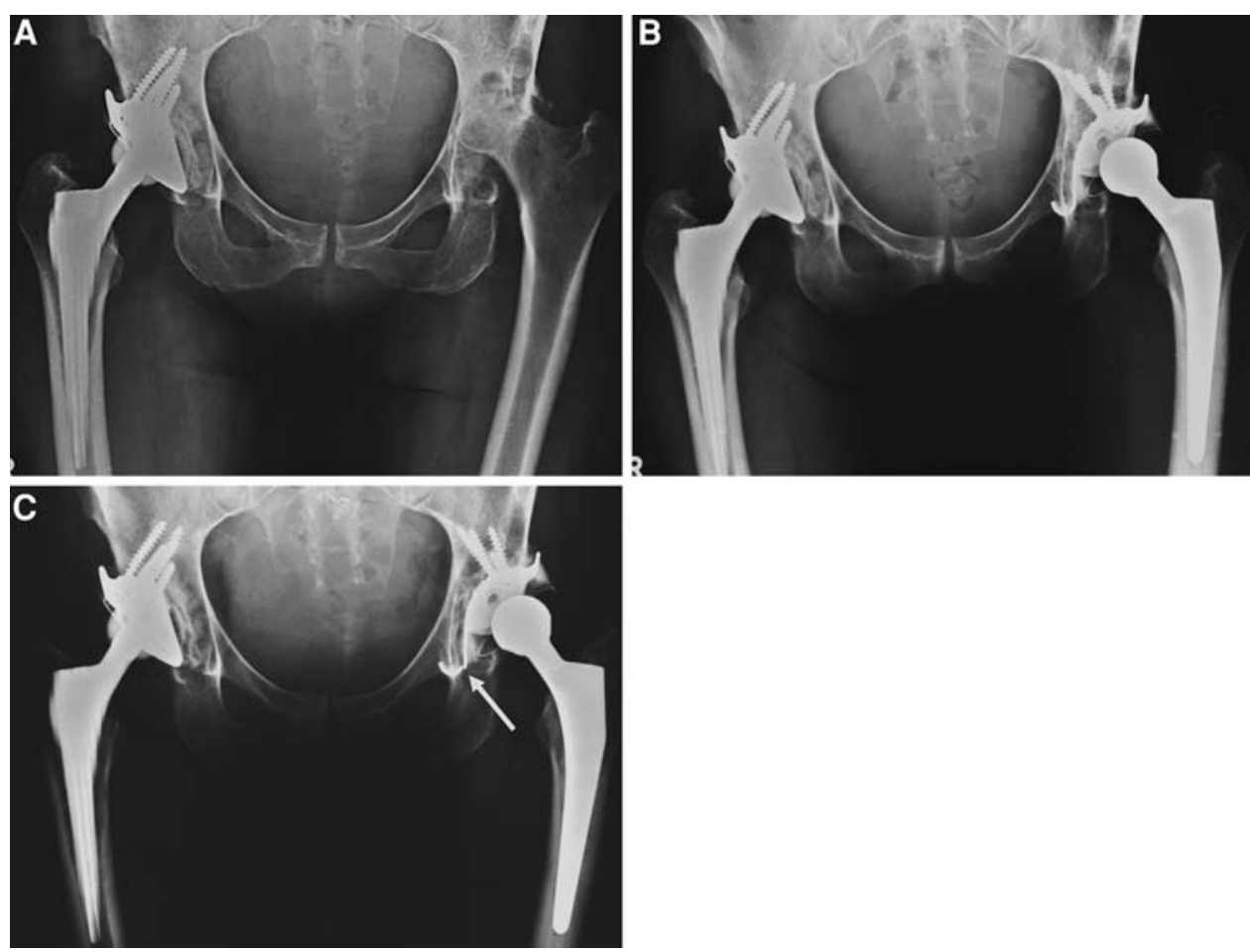

\begin{tabular}{lllllll}
\hline Case & Primary diagnosis & $\begin{array}{l}\text { Broken } \\
\text { screws }\end{array}$ & Migration & $\begin{array}{l}\text { Continuous } \\
\text { radiolucency }\end{array}$ & $\begin{array}{l}\text { Broken } \\
\text { hook }\end{array}$ & Merle-d'Aubigné score \\
\hline 1 & Osteonecrosis & + & + & + & + & 17 \\
2 & Dysplasia & + & + & + & 14 \\
3 & Osteonecrosis & & + & + & 17 \\
4 & Osteoarthrosis & & + & + & 7 \\
5 & Osteonecrosis & & + & + & 18 \\
6 & Osteoarthrosis & + & + & & 12 \\
7 & Rheumatoid Arthritis & + & + & & & 18 \\
\hline
\end{tabular}

Survival analysis

The probability of survival of the cup at 10 years was 0.97 (95\% confidence interval, 0.94 and 0.99) (Fig. 4). Multivariate results indicated that patient gender $(P=0.55)$, age $(P=0.32)$, preoperative Merle-d'Aubigné score $(P=0.11)$ and the position of the implants hook $(P=0.17)$ did not have a statistically significant impact on survivorship of the implant.

\section{Discussion}

Despite advances in technique, aseptic loosening remains the greatest challenge in the long-term survival of cemented and uncemented THA. Revision rates for aseptic loosening with migration of the prosthetic acetabulum were reported in up to $15 \%$ for cemented and $7.1 \%$ for uncemented cups $[40,42]$. Following the observation of the encouraging

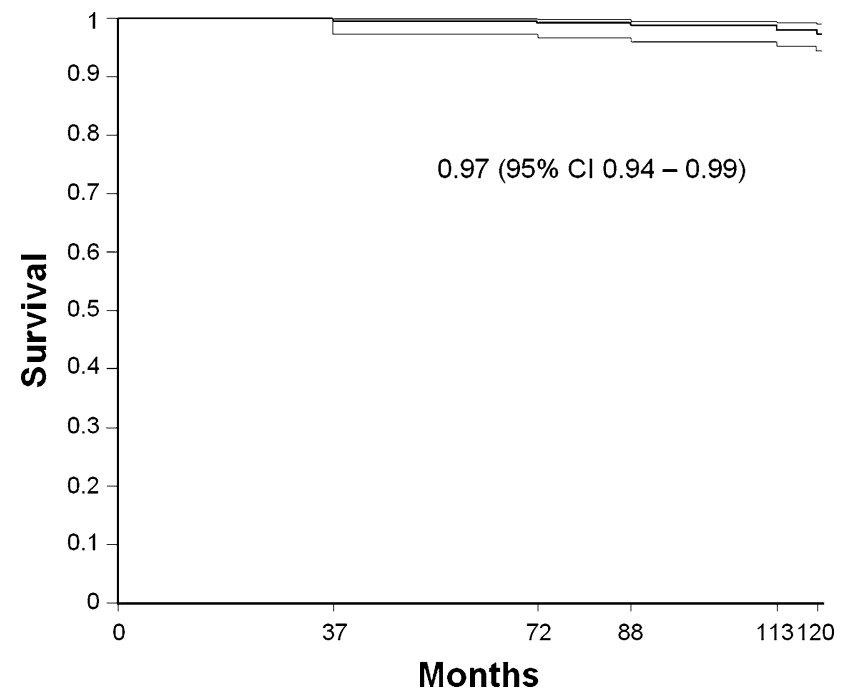

Fig. 4 Probability of survival of the acetabular component $(C I=$ confidence interval) 
Table 3 Selected literature overview on survivorship and migration of different cups

\begin{tabular}{|c|c|c|c|c|c|c|c|}
\hline Authors & Year & Type of cup & $N$ & Mean age (years) & Mean follow-up (years) & Survivorship cup (\%) & Migration cup (\%) \\
\hline Older et al. [27] & 1986 & Cemented & 217 & 66 & $10-12$ & - & 8 \\
\hline Mulroy et al. [26] & 1995 & Cemented & 162 & 61 & $15(14-17)$ & 88 & 13 \\
\hline Madey et al. [23] & 1997 & Cemented & 356 & 69 & Minimum 15 & $89(83-95)$ & 9 \\
\hline Smith et al. [36] & 1997 & Uncemented & 52 & 57 & $12.3(11-13)$ & - & 2 \\
\hline McAuley et al. [24] & 1998 & Uncemented & 212 & 65 & $8.2(5-14)$ & $92(85-99)$ & 2 \\
\hline Clohisy et al. [8] & 1999 & Uncemented & 120 & 59 & $10(7-13)$ & $96(92-100)$ & 0 \\
\hline Xenos et al. [43] & 1999 & Uncemented & 100 & 66 & $11.6(10-13)$ & $93(90-96)$ & 12 \\
\hline Archibeck et al. [3] & 2001 & Uncemented & 92 & 52 & $10(7-11)$ & 96.4 & 2 \\
\hline Kawamura et al. [20] & 2001 & Uncemented & 154 & 61 & 10 & 97.7 (95-99) & 5 \\
\hline Grübl et al. [13] & 2002 & Uncemented & 208 & 61 & 10 & $93(89-97)$ & 0 \\
\hline Aldinger et al. [2] & 2004 & Uncemented $^{\mathrm{a}}$ & 127 & 57 & 13.3 & 76.2 & 7 \\
\hline Aldinger et al. [2] & 2004 & Uncemented $^{\mathrm{b}}$ & 221 & 57 & 11.9 & 63.8 & 10 \\
\hline Blacha [5] & 2004 & Uncemented & 65 & 44 & $7(5-9)$ & $69(61-77)$ & 5 \\
\hline Oosterbos et al. [28] & 2004 & Uncemented & 100 & 72 & 10 & 97 (94-99) & 0 \\
\hline Shetty et al. [33] & 2004 & Uncemented & 134 & 75 & $14.2(13-15)$ & $100 \%$ & 0 \\
\hline Hendrich et al. [16] & 2006 & Uncemented & 92 & 53 & $11(1-18)$ & $71 \%$ & 42 \\
\hline Reikeras et al. [31] & 2006 & Uncemented $^{c}$ & 128 & 49 & $13(11-16)$ & $91(86-97)$ & 2 \\
\hline Reikeras et al. [31] & 2006 & Uncemented $^{\mathrm{d}}$ & 195 & 47 & $13(11-16)$ & $74(69-80)$ & 3 \\
\hline Castoldi et al. [7] & 2007 & Uncemented & 157 & 59 & 10 & 92.6 & - \\
\hline Garcia-Rey et al. [10] & 2007 & Uncemented $^{\mathrm{e}}$ & 93 & 64 & $10.6(7-12)$ & $97.6(94-100)$ & 4 \\
\hline Garcia-Rey et al. [10] & 2007 & Uncemented $^{\mathrm{f}}$ & 83 & 57 & $15.5(3-19)$ & 93.8 (89-99) & 5 \\
\hline Surdam et al. [38] & 2007 & Uncemented & 231 & 53 & $9(5-14)$ & 99 & 3 \\
\hline Present study & 2007 & ARRH & 241 & 58 & $12(10-15)$ & 97 (94-99) & 2.9 \\
\hline
\end{tabular}

ARRH Acetabular reinforcement ring with hook

${ }^{\text {a }}$ Weill

${ }^{b}$ Mecring

c Threaded cup

d Press fit cup

${ }^{\mathrm{f}}$ Harris Galante I

e Harris Galante II

results seen with the use of the traditional Müller acetabular reinforcement ring in primary THA $[1,15]$ and revision arthroplasty $[14,37,44]$ as well as excellent results of the ARRH in dysplastic hips [34], avascular necrosis of the femoral head [21] and revision cases [11,35], the senior author supposed that this implant would provide equivalent or superior results in primary THA in terms of survivorship and migration. The ARRH is unlike a standard cemented cup as there is no cement bone interface. Little reaming of bone is required in comparison to pressfit implants and thus more subchondral bone is preserved. There is a homogenous load distribution to the acetabulum, which may be important in cases with reduced bone quality like in patients with osteopenia or with bone loss due to underlying pathology such as rheumatoid arthritis or late stage osteonecrosis of the femoral head. The cumulative 10-year survivorship of the ARRH of $97 \%$ is superior to classic cemented techniques and comparable to modern cementless implants with a similar follow-up (Table 3). Similarly, the migration rate of $2.9 \%$ of the ARRH is lower in comparison to most cemented techniques and equivalent or even lower to uncemented sockets.

This study has limitations. Besides the lack of a control group, our series consists of a diverse patient group, which is difficult to compare with other published series of primary total hip replacement. Secondary referral to our center of more complicated cases and those with bone stock deficiencies may compromise the long-term results of our implant. Only $59 \%$ of patients had a diagnosis of primary OA, which is substantially lower in comparison to other studies where up to $97 \%$ of the patients presented with primary OA [28, 33]. In addition, 50 of our patients $(21 \%)$ had previous operations around the hip joint, which included mainly intertrochanteric osteotomies $(16 \%)$. This of course can lead to inferior long-term results [30]. In addition, we must remember to critically evaluate cases in our series 
with definitive signs of radiographic loosening, especially those that were symptomatic. It is known that loosecemented sockets may remain asymptomatic [41, 42] and nonprogressive radiolucent lines in cases of a reinforcement ring are not always associated with implant failure [15]. This may be related to the implantation technique itself, as absence of an absolute snug fit between the ARRH and the subchondral bone may be frequently seen in cases without cancellous bone grafting. Progressive radiolucent lines however correlate with migration of the reinforcement ring and breakage of the hook and screws, which has to be considered as an implant failure [15, 32].

Interestingly, in the radiographically loose cases no extensive osteolysis was seen around the screws and the lesions remained linear with a maximal width of $2 \mathrm{~mm}$. No cavitary lesions were seen as described by other authors [30] and none showed protrusion. Protrusion may be prevented in this case by the larger load distribution of the ring, as well as the hook, which may be especially important in compromised bone stock. A largely preserved acetabulum bears the advantage that good bone stock is maintained in the case of revision surgery. Preservation of bone stock is facilitated by the fact that extraction of the ARRH is relatively easy without sacrificing significant subchondral bone. All but one of the revised cases underwent reimplantation with a new, slightly larger ARRH. An additional point of versatility in this acetabular implant is that it permits the exchange of the polyethylene cup as well as alterations in orientation without removal of the metallic ring. This is an advantage, when the polyethylene component needs to be exchanged in case of premature wear or in the event of dislocation due to improper orientation. This again, helps preserve bone stock because the ring itself does not have to be removed.

In our series, a low migration rate was observed when comparing the results to the literature (Table 3). Seven of our non-revised cases had migrated and therefore were definitely considered radiologically loose. In four other cases a single broken screw was detected without any further radiographic sign of loosening over a subsequent follow-up period of $8-12$ years. All of these patients continued to have good to excellent clinical scores. Thus, these implants were not considered loose especially since the screw breakage was detected early in three of the four cases within 27 months potentially during the period of definitive seating of the implant. This phenomenon might be explained by the relative elasticity of the titanium reinforcement ring with potential deformation under load. Although not press fit, the oval geometry and the inferior hook may play an additional role in stability, preventing rotation and migration of the component. When comparing our migration rate to modern cementless cups, only few of them are superior (Table 3). However, this might be due to several circum- stances such as another definition for cup migration (greater than $4 \mathrm{~mm}$ of movement of the center of rotation vertically or horizontally) [8, 36, 43], a substantial higher number of patients with primary OA $[28,33]$, or a considerable higher number of deceased patients [28].

In summary, the excellent results observed after THA in a consecutive group of patients with both primary and secondary arthritis supports the consistent use of this implant in primary total hip arthroplasty. It is indicated in cases with qualitative (e.g. rheumatoid arthritis or avascular necrosis of the femoral head) and quantitative (e.g. protrusion, dysplasia) loss of the retroacetabular bone stock. The advantages of bone preservation and versatility of the implant contribute to our reasoning behind its routine use.

\section{References}

1. Aebi M, Richner L, Ganz R (1989) Long term results of primary hip total prosthesis with acetabulum reinforcement ring. Orthopäde 18:504-510 (In German)

2. Aldinger PR, Thomsen M, Lukoschek M, Mau H, Ewerbeck V, Breusch SJ (2004) Long-term fate of uncemented, threaded acetabular components with smooth surface treatment: minimum 10year follow-up of two different designs. Arch Orthop Trauma Surg 124:469-475

3. Archibeck MJ, Berger RA, Jacobs JJ, Quigley LR, Gitelis S, Rosenberg A, Galante JO (2001) Second-generation cementless total hip arthroplasty. J Bone Joint Surg Am 83:1666-1673

4. Bauer R, Kerschbaumer F, Poisel S, Oberthaler W (1979) The transgluteal approach to the hip joint. Arch Orthop Trauma Surg 95:47-49

5. Blacha J (2004) High osteolysis and revision rate with the hydroxyapatite-coated ABG hip prostheses: 65 hips in 56 young patients followed for 5-9 years. Acta Orthop Scand 75:276-282

6. Brooker AF, Bowerman JW, Robinson RA, Riley LH (1973) Ectopic ossification following total hip replacement. Incidence and a method of classification. J Bone Joint Surg Am 55:1629-1632

7. Castoldi F, Rossi R, La Russa M, Sibelli P, Rossi P, Ranawat AS (2007) Ten-year survivorship of the Anatomique Benoist Girard I total hip arthroplasty. J Arthroplasty 22:363-368

8. Clohisy JC, Harris WH (1999) The Harris-Galante uncemented femoral component in primary total hip replacement at 10 years. $\mathrm{J}$ Arthroplasty 14:915-917

9. Cox DR (1972) Regression models and life-tables (with discussion). J Roy Statist Soc Ser B Method 34:187-220

10. Garcia-Rey E, Garcia-Cimbrelo E (2007) Long-term results of uncemented acetabular cups with an ACS polyethylene liner. A 14-16-year follow-up study. Int Orthop 31:205-210

11. Gerber A, Pisan M, Zurakowski D, Isler B (2003) Ganz reinforcement ring for reconstruction of acetabular defects in revision total hip arthroplasty. J Bone Joint Surg Am 85:2358-2364

12. Goodman SB, Adler SJ, Fyhrie DP, Schurman DJ (1988) The acetabular teardrop and its relevance to acetabular migration. Clin Orthop Relat Res 236:199-204

13. Grübl A, Chiari C, Gruber M, Kaider A, Gottsauner-Wolf F (2002) Cementless total hip arthroplasty with a tapered, rectangular titanium stem and a threaded cup: a minimum 10-year follow-up. J Bone Joint Surg Am 84:425-431

14. Gurtner P, Aebi M, Ganz R (1993) The acetabular roof cup in revision arthroplasty of the hip. Z Orthop Ihre Grenzgeb 131:594-600 (In German) 
15. Haentjens P, de Boeck H, Handelberg F, Casteleyn PP, Opdecam $P$ (1993) Cemented acetabular reconstruction with the Müller support ring. A minimum 5-year clinical and roentgenographic follow-up study. Clin Orthop Relat Res 290:225-235

16. Hendrich C, Mehling I, Sauer U, Kirschner S, Martell JM (2006) Cementless acetabular reconstruction and structural bone-grafting in dysplastic hips. J Bone Joint Surg Am 88:387-394

17. Hosmer DW, Lemeshow S (1999) Applied logistic regression. Wiley, New York, pp 40-52

18. Johnston RC, Fitzgerald RH, Harris WH, Müller ME, Sledge CB (1990), Clinical and radiographic evaluation of total hip replacement. J Bone Joint Surg Am 72:161-168

19. Kaplan E, Meier P (1958) Nonparametric estimation from incomplete observations. J Am Stat Assoc 53:457-481

20. Kawamura H, Dunbar MJ, Murray P, Bourne RB, Rorabeck CH (2001) The porous coated anatomic total hip replacement: a ten to fourteen-year follow-up study of a cementless total hip arthroplasty. J Bone Joint Surg Am 83:1333-1338

21. Koch PP, Tannast M, Fujita H, Siebenrock KA and Ganz R (2008) Minimum ten year results of total hip arthroplasty with the acetabular reinforcement ring in avascular osteonecrosis. Int Orthop, in press

22. Livermore J, Ilstrup D, Morrey B (1990) Effect of femoral head size on wear of the polyethylene acetabular component. J Bone Joint Surg Am 72:518-528

23. Madey SM, Callaghan JJ, Olejniczak JP, Goetz DD, Johnston RC (1997) Charnley total hip arthroplasty with use of improved techniques of cementing. The results after a minimum of fifteen years of follow-up. J Bone Joint Surg Am 79:53-64

24. McAuley JP, Moore KD, Culpepper WJ, Engh CA (1998) Total hip Arthroplasty with porous-coated prostheses fixed without cement in patients who are sixty-five years of age or older. J Bone Joint Surg Am 80:1648-1655

25. Merle d'Aubigné R, Postel M (1954) Functional results of hip arthroplasty with acrylic prosthesis. J Bone Joint Surg Am 36:451-475

26. Mulroy RD, Harris WH (1990) Failure of acetabular autogenous grafts in total hip arthroplasty. Increasing incidence: a follow-up note. J Bone Joint Surg Am 72:1536-1540

27. Older J (1986) Low-friction arthroplasty of the hip. A 10-12-year follow-up study. Clin Orthop Relat Res 211:36-42

28. Oosterbos CJ, Rahmy AI, Tonino AJ, Witpeerd W (2004) High survival rate of hydroxyapatite-coated hip prostheses: 100 consecutive hips followed for 10 years. Acta Orthop Scand 75:127-133

29. Pagnano MW, Hanssen AD, Lewallen DG, Shaughnessy WJ (1996) The effect of superior placement of the acetabular component on the rate of loosening after total hip arthroplasty. Long-term results in patients who have Crowe type-II congenital dysplasia of the hip. J Bone Joint Surg Am 78:1004-1014
30. Raut VV, Siney PD, Wroblewski BM (1996) Revision of the acetabular component of a total hip arthroplasty with cement in young patients without rheumatoid arthritis. J Bone Joint Surg Am 78:1853-1856

31. Reikeras O, Gunderson RB (2006) Long-term results of HA coated threaded versus HA coated hemispheric press fit cups: 287 hips followed for 11 to 16 years. Arch Orthop Trauma Surg 126:503508

32. Rosson J, Schatzker J (1992) The use of reinforcement rings to reconstruct deficient acetabula. J Bone Joint Surg Br 74:716-720

33. Shetty AA, Slack R, Tindall A, James KD, Rand C (2005) Results of a hydroxyapatite-coated (Furlong) total hip replacement: a 13 to 15-year follow-up. J Bone Joint Surg Br 87:1050-1054

34. Siebenrock KA, Tannast M, Kim S, Morgenstern W, Ganz R (2005) Acetabular reconstruction using a roof reinforcement ring with hook for total hip arthroplasty in developmental dysplasia of the hip-osteoarthritis minimum 10-year follow-up results. J Arthroplasty 20:492-498

35. Siebenrock KA, Trochsler M, Sadri H, Ganz R (2001) Hooked roof cup in revision of difficult loose hip prosthesis cups. Results after a minimum of 10 years. Orthopäde 30:273-279 (In German)

36. Smith SE, Harris WH (1997) Total hip arthroplasty performed with insertion of the femoral component with cement and the acetabular component without cement. Ten to thirteen-year results. J Bone Joint Surg Am 79:1827-1833

37. Stockl B, Beerkotte J, Krismer M, Fischer M, Bauer R (1997) Results of the Müller acetabular reinforcement ring in revision arthroplasty. Arch Orthop Trauma Surg 116:55-59

38. Surdam JW, Archibeck MJ, Schultz SC, Junick DW, White RE (2007), A second-generation cementless total hip arthroplasty mean 9-year results. J Arthroplasty 22:204-209

39. Tannast M, Langlotz U, Siebenrock KA, Wiese M, Bernsmann K, Langlotz F (2005) Anatomic referencing of cup orientation in total hip arthroplasty. Clin Orthop 436:144-150

40. Thomas BJ, Saa J, Lane JM (1996) Total hip arthroplasty. Curr Opin Rheumatol 8:148-153

41. Wroblewski BM, Fleming PA, Siney PD (1999) Charnley lowfrictional torque arthroplasty of the hip: 20 - to 30 -year results. J Bone Joint Surg Br 81:427-430

42. Wroblewski BM, Siney PD (1993) Charnley low-friction arthroplasty of the hip. Long-term results. Clin Orthop Relat Res 292:191-201

43. Xenos JS, Callaghan JJ, Heekin RD, Hopkinson WJ, Savory CG, Moore MS (1999) The porous-coated anatomic total hip prosthesis, inserted without cement. A prospective study with a minimum ten years of follow-up. J Bone Joint Surg Am 81:74-82

44. Zehntner MK, Ganz R (1994) Midterm results (5.5-10 years) of acetabular allograft reconstruction with the acetabular reinforcement ring during total hip revision. J Arthroplasty 9:469-479 